\title{
People with Disabilities: The Underserved and Unserved
}

Author:

Li-Rong Lilly Cheng

San Diego State University

Sandra Levey

City University of New York

\section{Correspondence:}

Professor Li-Rong Lilly Cheng

San Diego State University, P.O.

Box 9364, Rancho Santa Fe,

California 92067, USA.

Email: $\underline{\text { lcheng@mail.sdsu.edu }}$

\begin{abstract}
There are estimated to be a growing number of asylum-seekers across the world, with the expectation that this number will exceed 60 million during 2016. A significant number of refugees and immigrants are disabled to one degree or another, with many disabilities resulting from the ravages of warfare or because of the poor health conditions in camps. Thousands of families that have been displaced have been left without health care. These are the underserved and unserved. The purpose of this paper is to present three models that offer innovative methods for providing services to underserved/unserved populations. These models examine the sustainability of approaches that support the transfer and the exchange of knowledge between Minority and Majority World settings. This paper further addresses the need for providing innovative solutions and capacity building for global issues that affect health care and the habilitation and rehabilitation of people with disabilities.
\end{abstract}

Key words: Disability, methods, capacity building, sustainability, underserved, unserved 


\section{Preface}

Given a world population of 7.4 billion people, one in every 113 is now an asylum-seeker, internally displaced, stateless or a refugee. In 2015-2016, the number of displaced people is expected to exceed 60 million [1]. These are figures considered unprecedented by the UN Human Rights Council [2]. There are a great number of displaced people in Southeast and Central Asia, the Middle East, Central and Eastern Europe, as well as in parts of Africa. There are thousands of children and families in the world who have been displaced and are now stateless and left without family and health care. Eighty per cent of people with disabilities live in developing countries, while The World Bank estimates that 20 per cent of the world's poorest people have some types of disability [3]. These are the unserved and underserved. In the face of the absence of adequate health services for this population, the number of disabled children is predicted to increase over the next 30 years across the world, particularly in developing countries due to malnutrition, diseases, child labor, and other causes.
The special needs of all people with disabilities must be met, and obstacles and barriers must be removed to meet their needs [4]. Effective communication, a human right, must be made accessible and achievable for all [5]. To address the needs of the unserved and underserved, there are some questions to be considered when planning a coordinated effort to meet their needs: Why are services so important? Why is it essential to advocate communication as a human right? Is there a shared vision across the world? Who are the stakeholders? What are the goals and objectives in improving the quality of life of ALL people? Although knowing full well that it is an uphill battle to address the barriers that affect the silent people with disability (PWD), addressing these barriers continues to remain an important mission.

\section{Introduction}

An estimated $15 \%$ of the entire world population experiences some form of disability, consisting of a billion or more people with a disorder [6]. These figures likely represent an underestimate of the prevalence of disabilities, given 
that the method of conceptualizing disability differs across the globe and that the surveys were conducted more than a decade ago [7]. To this end, an effort is underway to establish an international standardization of measurement to promote the development of systematic outcomes [8]. A global definition and consensus on the conceptualization of human communication disability is necessary so that actual data can be gathered for analysis and applied to planning health approaches for the changing landscape in health care [9].

The argument presented in the current article is that there are many underserved/unserved populations across the world whose needs are not being met. There is a lack of equity across populations in the Majority and Minority Worlds that require services, along with a disparity and large gap between countries in the delivery of services for populations with communication disorders.

According to the International Migration Report [10], the number of international migrants worldwide has reached 244 million in 2015, up from 222 million in 2010 and 173 million in 2000. Speech language pathologists (SLPs) and other practitioners must be provided with realistic solutions to the needs of immigrants, refugees, and other underserved populations. It is important to design new approaches that are culturally relevant, holistic, accessible, sustainable, and responsive to the needs of these populations. One of the solutions is a collaboration between SLPs in Minority World countries and Majority World Countries to develop methods to provide services to populations that require assistance and to facilitate twoway learning.

\section{Overview}

In this complex world, thousands of children and families go hungry each night as their basic needs for food and safety are not met. In Aleppo, it was reported that there were only 35 doctors for a population of 300,000 [11]. There are also thousands of women who die of childbirth trauma. In 2015, the maternal mortality ratio (the number of maternal deaths per 100, 000 live births) was estimated at a global number of 
approximately 830 women dying every single day, resulting from complications that existed during pregnancy and childbirth [12]. This report stated that these deaths mainly occurred in lowresource settings, and that most could have been prevented. There are considerable differences that exist in reproductive, maternal, newborn, and child health intervention coverage across countries, with many countries having less than $10 \%$ coverage to address these needs [12]. The WHO argues that effective prevention strategies must include sustainable solutions for access to an appropriate diet, financial support for the distribution of nutrient-dense food supplements, access to safe water, and the development of sanitation and health care services.

As the result of warfare and conflict across the world, people are exposed to the spread of diseases, nutrition, and the collapse of health care services. Children born in war torn areas have little or no health care, and adults have little access to medical care services. In many areas of the world, medical services are difficult to access, are inadequate, or are unavailable
[13]. On the other hand, health corporations have emerged with the goal of providing medicines and health services at an affordable cost [14], partnering with several governments and nonprofit organizations in an effort to provide clean water across the globe. This is an important contribution, since it is reported that 700 million are using unimproved sources or surface water [12].

An example of the difficulties faced by populations affected by government breakdown and civil war is found in the refugee camp that existed in Calais, France, locally known as the New Jungle [15]. This camp provided refuge for an estimated 10,000 people from Iraq and Syria. The population of this camp was largely unwell due to unsanitary conditions, with no electricity and water available from only three water points in the camp. The dismantling of the camp involved the movement of an estimated 1,300 unaccompanied child refugees to the UK and other sites, with serious concerns about these children's welfare. Children risked their lives on the average of 2,110 times a week to reach families 
and safety, stowing away in the backs of trucks and trying to jump on trains [16].

There are also examples of countries that are not suffering from warfare or conflict that have deficiencies in providing adequate health services to people with disabilities. China, the most populous country in the world with a population of 1.4 billion, has only a handful of formal academic training programs for the education and training of speech language pathologists in some large cities including Beijing, Shanghai, Guangzhou, Nanjing, and Kunming $[17,18]$. In general, there are inadequate services for diagnostics and intervention to address communication disorders (e.g., speech, language, hearing, swallowing, or stroke). There are also asymmetries in the communication of information between patients and health care providers that make it difficult for the populace to make sound choices. However, China has unveiled an action plan for universal access to basic health care [19]. This three-year plan for health care reform is intended to lay a foundation for equitable and universal access for health care for all by 2020 . In contrast, countries such as
Finland and Sweden provide excellent models for health care practices. Healthcare services are universal, with all residents covered by public healthcare and reimbursed for the costs of medicine and the use of private healthcare services.

\section{Creating Solutions}

Three models have been provided that can be adopted and then adapted to address problems in health care and to institute changes in the provision of services to underserved and/or unserved populations [20,21]. These three models are presented to bring hope and inspiration that encourages people to come together to plan and create a more optimal environment for families and children with disabilities. This group may consist of people who share the same dialect and culture and live in close proximity, yet have very large gaps in knowledge and services in their region. This model is accessible, sustainable, culturally relevant, and responsive. The first model describes this approach when working with autism spectrum disorders (ASD). The University of Guangzhou was charged with training teachers to improve 
their knowledge and skills when working with the special needs populations. In 2016, the Guangzhou Bureau of Education sponsored a three-year grant to offer continuing education on special education and human communication disorders to a selected number of teachers [22] This project addressed a crucial need, given that a review of service provision to children with ASD in China found poor knowledge of and experience with this disorder, with the need to improve services to this population [23].

To address the need for major improvement of the education of children with ASD, professionals in Hong Kong, Taiwan, and the US met to address this goal. Services in Hong Kong are quite advanced, with 18 private agencies and 19 non-government organizations (NGOs) that provide services for children with ASD. In addition, the Autism Children Foundation (ACF) was founded by a group of parents and specialists in 2005 . Based on the collective efforts of SLPs and audiologists, a series of training workshops were held in Guangzhou, China in 2013, 2014, and 2015. The main goal of this collaboration was to educate practitioners about $\mathrm{ASD}$ and to improve the quality of education and services for children with this disorder, along with assistance to their families. More than two thousand teachers participated in these workshops to learn about ASD, and discussions were held on how services could be improved for children in need $[24,25]$. A survey of participants revealed the need to provide additional training for teachers to improve their knowledge and skills.

Following the collaborative discussion of autism, the following factors were identified as those that required additional knowledge on the part of teachers and other practitioners: social emotional needs and development, environmental factors that may impact on a child's behavior, identification of the sensory factors that may impact children's ability to remain focused in the classroom, reasons for so-called misbehaviors (hiding under a table, hiding in a closet, singing, or covering their ears), emotional regulation that requires support, and brain development that affects social emotional development. Knowledge of these factors is essential to 
ensure the provision of improved strategies, interventions, and resources for sensory processing disorders, including the use of visual and auditory aids for children who will benefit from these supports. It was further suggested to provide ASD-related medical training for physicians, focusing on the needs of underserved ASD children, providing service practice guidelines, issuing evidence-based policies for family support, enhancing public education to improve awareness and acceptance of ASD in the general population, education inclusion for these children, and with further research to provide feedback for service improvement [23].

The second model is designed to promote collaboration among different linguistic and cultural groups [20]: Capacity Building and Sustainability. The goal is for diverse groups of individuals to work together to educate and train the next generation of SLPs to serve underserved populations. This best practice model is culturally relevant and has proven to be sustainable and responsive. The goal of this program is to build capacity and resources to increase global involvement.

The Intensive Program (IP) has been an on-going education program in Europe for many years. The Department of Speech Language Therapy and Audiology (SLT) at Thomas More University College in Antwerp, Belgium initiated and developed this program. This program began with the participation of 14 universities/colleges in Europe with funding from the EU. From 1993 to 2010, they coordinated an Erasmus Lifelong Learning Intensive Program (IP) among SLP departments in Europe. This Intensive Program was funded by the European Commission on a yearly basis. However, funding from the EU stopped in 2011 with all participating institutions asked to contribute funds to sustain this innovative program. In 2011, Taiwan was invited to participate. In 2012, Hong Kong was invited to observe this program, while Macao was invited to observe in 2014. In addition, a university from the United States also participated in the program in 2014. In this program, faculty members are drawn from various countries and campuses to share their 
expertise and cutting edge information with student participants. The program consists of lectures and hands-on interactive seminars. Lectures are provided by faculty members of the partner institutions and guest lecturers. Innovative and emerging issues are the consistent topics of discussion, and students are provided with the opportunity to meet peer groups from many different linguistic and cultural groups. Students in the program are provided with the opportunity to learn about underserved populations and are encouraged to serve in areas where speech and language services are badly needed. In 2015, two SLPs from Suriname described their work [26]. They shared information on the needs of their people and engaged staff and students in discussion on how best to bring solutions to the underserved and unserved areas. Students of the IP intensive program also attended the 2016 Congress of the International Association of Logopedics and Phoniatrics (IALP), which was held in Dublin, Ireland. These participants had the opportunity to meet with delegates from over 61 countries, attended lectures, and interacted with multilingual and multicultural professionals. Cooperation between different SLP departments creates an excellent opportunity to move towards coordination of SLP programs and provides the opportunity to engage in joint multilateral research. This European program has reached out to Asia, Africa and America, building a SLP-IP network that connects individuals across the globe.

The third model demonstrates the use of technology to serve remote rural areas [20]. The model is intended to be accessible, holistic, organic, and sustainable. A telecommunication company with its headquarter located in San Diego, California demonstrated the use of advanced wireless technology to improve health care, education and entrepreneurship in China [27]. This global company launched a project for rural China using wireless technology in 2006. This project used $3 \mathrm{G}$ mobile devices to connect rural and urban doctors to improve patient care in China. The Qualcomm Mobile Vision Project builds on the knowledge that they have gained over the decade to help improve patient care in rural communities. China has 
more than 1.4 billion people. Access to health care resources is severely compromised in many underserved, rural, and remote areas of this country. It has been reported that there are approximately 1.6 physicians and 1.8 nurses per 1000 people available for services [28]. These statistics show that China has fewer doctors per person than the average for advanced industrial economies (3.2 physicians and 8.8 nurses per thousand). Many people have lost their lives because of the lack of access to medical care and medication. To address this situation, Project 3G Mobile Medicine demonstrated how 3G wireless technology could be used in rural health clinics to extend the reach of clinicians and improve patient care for underserved populations and marginalized communities.

This technology project gives urban and rural doctors mobile devices such as smart phones and $3 \mathrm{G}$ enabled PCs. This will allow them to access an application with helpful health care information. The application has Electronic Health Records, so that designated health care workers can locate and receive confidential access to a patient's medical chart via a computer or mobile phone at any time and location by using 3G Internet access. Participating clinics can also share records, which ensures continuity of care across different clinics. This is crucial for sustainable care. This application also has access to Rural Health Care Content by which clinicians can use cell phones and $3 \mathrm{G}$ enabled PCs to access educational and treatment content that is designed to address the specific needs of rural doctors. This information provides methods for the treatment of common medical problems, such as respiratory illnesses and broken bones, as well as information on preventative medicine. Access to this new information improves the ability of clinicians to more efficiently diagnose and treat a broader range of illnesses, an ability that was not available to practitioners before access to this technology. This technology provides remote consultation by which rural doctors can consult with physicians in other participating clinics and with urban doctors, allowing each to benefit from the expertise of other practitioners and further increasing the potential for effective 
treatment. This specific technology uses 3G mobile broadband connectivity via China Telecom's network, 3G enabled smartphones powered by Qualcomm chipsets, and Internet ready PCs. This is a specialized mobile application that synchronizes in real-time with a customized web that allows easy access to other clinicians, educational information, and patient health records. Since 2011, the project has been expanded to 21 clinics in Xian County, Hebei Province, and approximately 150 rural doctors. All participants have received instruction on how to use the application and devices, as well as additional medical and technical training. More than 160,000 patients have benefitted from the program, some of whom are managing chronic cardiovascular diseases (CVD), and some of whom were screened for the first time. Many of these patients are rural and do not have access to high-quality medical care [27].

Multiple partners have been involved in this project including $\mathrm{Xi}$ 'an Kingtone, which oversees project implementation and application development; China Telecom which provides $3 \mathrm{G}$ connectivity at a subsidized rate; China Children and Teenagers' Fund, which provides assistance in conducting a needs assessment, site selection, training, and project implementation; and China Rural Doctors Training Center, which provides doctor training, mobile content, and identified physicians and experts to offer remote medical consultation to rural doctors. This model can certainly be modified to include speech and hearing professional services. The key element of this model is collaboration among government, industry, the community, and professionals.

\section{Updates and Current}

\section{Challenges}

The goal of this article is to contribute to the discussion of approaches to providing services to underserved /unserved populations. Meeting local needs requires innovation and strategies for thinking outside the box. What works in one part of the world may have less effective results in another part of the world. However, the essential ingredients for building capacity and sustainability include care, passion, compassion, 
dedication, collaboration, and commitment. Understanding the physical, environmental, political, social, cultural, linguistic, and local needs of the target population is a necessary step in providing relevant, sustainable, and scalable solutions.

Throughout one's life span, one may experience one type or another of disability. Disability has medical, psychological, social, environmental, and political dimensions. The medical dimension is the responsibility of medical doctors and rehabilitation professionals, including occupational therapists, physical therapists, audiologists, and speech language pathologists. The psychological domain of disability is the responsibility of psychologists and social workers. The social dimension of disability includes methods and programs developed by the government to address the care and needs of people with disabilities. The government's role may be influenced by how disability is viewed within the society. There are also environmental aspects of disability that require special accommodation and access to public transportation and buildings with the use of ramps. Additionally, there is need for supports for blind individuals that consist of Braille in elevators and other public places, along with accommodations for the deaf that consist of captions to ease and aid their communication.

\section{Conclusion}

Some disabilities are visible, such as the loss of a limb or blindness. Other disabilities are sometimes less visible, such as deafness, a reading disability, autism, attention deficit hyperactivity disorders, and sensory processing disorders. Given the global increase in the prevalence of these disorders, SLPs must be aware of the challenges faced by these children, their parents, and their teachers to help develop the skills required for their self-regulation and emotional awareness. It is important to understand how to create an optimal learning environment. Understanding the importance of social emotional development, along with approaches to these behaviors and the environmental factors, will make a child's behavior less challenging and help in managing these 
behaviors. There is a need to raise the silent voices for many PWDs and people with communication disorders (PWCDs). Advocating for quality service and fighting for their communication rights cannot wait. Quoting the words of Nobel Laureate Gabriela Mistral is appropriate here:

"We are guilty of many errors and many faults, but our worst crime is abandoning the children, neglecting the fountain of life. Many of the things we need can wait. The child cannot. Right now is the time his bones are being formed, his blood is being made, and his senses are being developed. To him we cannot answer 'Tomorrow,' his name is today." 


\section{References}

1. David, F. (2016). Distress Migration and Modern Slavery. Retrieved from http://assets.globalslaveryindex.org/do wnloads/Distress\%20Migration\%20\% 20and $\% 20$ Modern $\% 20$ Slavery $\% 20 \% 5$ BFiona\%20David\%5D.pdf

2. Edwards, A. (2016). Global forced displacement hits record high. The UN Refugee Agency. Retrieved from http://www.unhcr.org/enus/news/latest/2016/6/5763b65a4/glob al-forced-displacement-hits-recordhigh.html

3. Disabled World Toward Tomorrow (2016). Definition: defining the meaning of annual disability status report. http://www.disabledworld.com/disability/statistics/

4. United Nations International Disability Alliance (2016). Transforming our world: the 2030 agenda for sustainable development. Retrieved from http://www.internationaldisabilityallia nce.org/sites/default/files/resources/do cuments/15/12/2030_agenda_for_sust ainable_development_web.pdf

5. American Speech-Language-Hearing Association (2016). Strategic pathway to excellence. Retrieved from http://www.asha.org/About/StrategicPathway/
6. World Health Organization (2011). World Report on Disability. Retrieved from http://www.who.int/disabilities/world report/2011/report/en/

7. McPhillips, D. (2016). Counting the world's invisible minority: for now, the number of people living with disability around the world is anyone's guess. Retrieved from http://www.usnews.com/news/bestcountries/articles/2016-09-07/lack-ofinternational-data-on-disability-issueshampers-advocates.

8. Porter, M., Larsson, S., \& Ingvar, M. (2012). A new initiative to put outcomes measurement at the center of health reform. Retrieved from http://healthaffairs.org/blog/2012/10/3 1/a-new-initiative-to-put-outcomesmeasurement-at-the-center-of-healthreform/

9. Sutherland, B., Burkard, R., McNeilly, L., Patashnik, B., Peach, R., Rao, P., Rogers, M., \& Shepard, N. (2012). ASHA changing health care landscape summit. Retrieved from http://www.asha.org/uploadedFiles/AS HA/Practice/Health-Care-

Reform/Healthcare-SummitExecutive-Summary2012.pdf\#search=\%22Rogers $\% 22$ 
10. United Nations (2015). International migration report. Retrieved from http://www.un.org/en/development/de sa/population/migration/publications/ migrationreport/docs/MigrationReport 2015_Highlights.pdf

11. PBS newshour (2016). Doctors without borders wants to expand in Aleppo. Retrieved from http://www.thirteen.org/programs/pbsnewshour/news-wrap-doctors-withoutborders-wants-to-expand-inaleppo_clip/

12. World Health Organization: World health statistics (2016). Retrieved from

http://www.marketwatch.com/story/th ermo-fisher-scientific-completesacquisition-of-life-technologiescorporation-2014-02-03

13. Grech, H. \& Cheng, L. (2016). Conceptual Framework for Speech Language Pathologists to Work with Migrants: A Focus on Malta. Journal of Education Issues. 2:2. Journal of Education Issues. 2:2.

14. Thermo Fisher Scientific (2016). Retrieved from http://corporate.thermofisher.com/cont ent/dam/tf/responsibility/Documents/2 015\%20CSR\%20Report\%20Final.co mpressed.pdf
15. The Guardian (2016). The horror of the Calais refugee camp: 'We feel like we are dying slowly. Retrieved from https://www.theguardian.com/world/2 015/nov/03/refugees-horror-calaisjungle-refugee-camp-feel-like-dyingslowly

16. Unicef (2016). Children risking their lives over 2,000 times a week to reach the UK. Retrieved from http://www.unicef.org.uk/Mediacentre/Press-releases/Children-riskingtheir-lives-over-2000-times-a-weekto-reach-the-UK

17. Chen, Z. (2015). Personal communication.

18. Huang, M, (2016). Personal Communication.

19. Yuan Ye, Y., \& Jiang, G. (2009). China to set up clinics in every village within 3 years. Retrieved from http://english.gov.on/200904/07/content_1279450.htm.

20. Cheng, L. (2013). Knowledge transfer between minority and majority world settings and its application to the world report on disability. International Journal of SpeechLanguage Pathology, 15(1), 65-68. Retrieved from http://dx.doi.org/10.3109/17549507.20 12.729862 
21. Cheng, L. (2015). Struggling to be seen and heard: the underserved and unserved populations. Folia Phoniatrica et Logopaedica, 66, (4-5), 212-216.

22. Education Bureau (2016). Circular Memorandum No. 57/2016. Retrieved from

http://www.edb.gov.hk/attachment/en/ sch-admin/admin/about-sch/sister-schscheme/EDBCM16057E.pdf.

23. Sun, X., Allison, C., Auyeung, B., Baron-Cohen, S., \& Brayne, C. (2013). A review of healthcare service and education provision of autism spectrum condition in mainland China. Research in Developmental Disabilities, 34, 469-479.

24. Sin, K. F. \& Yu, S. Ying. (2011). Education of students with autism: paper collection of Autism in seminars of Hong Kong and Guangzhou. Centre for Special Needs and Studies in Inclusive Education. Hong Kong: The Hong Kong Institute of Education.

25. Cheng, L., Wallach, G., \& Reed, V.A. (2014). ASHA SLPs in China teach teachers about their students with disabilities. Communication Disorders Quarterly, 19, 119-120.

26. Lieuw-Tjoen-Sioe, $\mathrm{N}$. (2016) Personal Communication.

27. Qualcomm (2016). Retrieved from https://www.qualcomm.com/news/onq /2016/09/30/how-mobile-technologyimproving-heart-health-china

28. Organization for Economic Cooperation and Development, 2014 (2014). Retrieved from http://www.oecd.org/els/healthsystems/Briefing-Note-CHINA2014.pdf 